\title{
Sézary syndrome preceded by mycosis fungoides and complicated by tumor lysis syndrome and macrophage activation syndrome
}

\section{Asmae Abdelmouttalib, Fatima Zahra Elghtaibi, Sanae Sialiti, Karima Senouci}

\author{
Dermatology and Venereology Department, Mohamed V University in Rabat, Morocco
}

Corresponding author: Asmae Abdelmouttalib, MD, E-mail: abdelmouttalibasmae@gmail.com

Sir,

Mycosis fungoides (MF) and Sézary syndrome (SS) are the most common malignancies of cutaneous T-cell lymphoma [1]. Herein, we report a case of SS complicated by tumor lysis syndrome and macrophage activation syndrome.

A 54-year-old patient, followed since October 2017 for mycosis fungoides and undergoing various treatments (PUVA therapy, methotrexate, chlorambucil + prednisone), presented with an aggravation of lesions toward extensive and intensely pruritic. A clinical examination revealed dry erythroderma, scratch marks, wart plaques, an accentuation of frontal wrinkles and nasolabial folds (leonine facies), palmoplantar fissuring keratoderma, xanthopachyonychia of all nails, and a carapace-like appearance of the scalp (Figs. 1 - 3). Generalized lymphadenopathy, hepatomegaly, and a state of anasarca-type edema caused by hypoalbuminemia were also found. A skin biopsy revealed lymphoproliferation of $\mathrm{CD}^{+}{ }^{+} \mathrm{T}$-cells and an aberrant loss of pan-T antigens. The CD4-toCD8 ratio was at $48.5 \%$ and Sézary cells were 6960 (absolute value). A lymph node biopsy showed a dense infiltration of Sézary cells. A PET scan revealed hypermetabolism in the entire skin and at the lymph node level. Tumor lysis syndrome was evident, with high levels of blood uric acid (at $182 \mathrm{mg} / \mathrm{L}$ ), elevated LDH (at $924 \mathrm{U} / \mathrm{L}$ ), and functional kidney failure. Macrophage activation syndrome was also present, with fever, anemia and thrombocytopenia, liver cytolysis, hypertriglyceridemia, and hyperferritinemia. The patient received an albumin infusion, oral

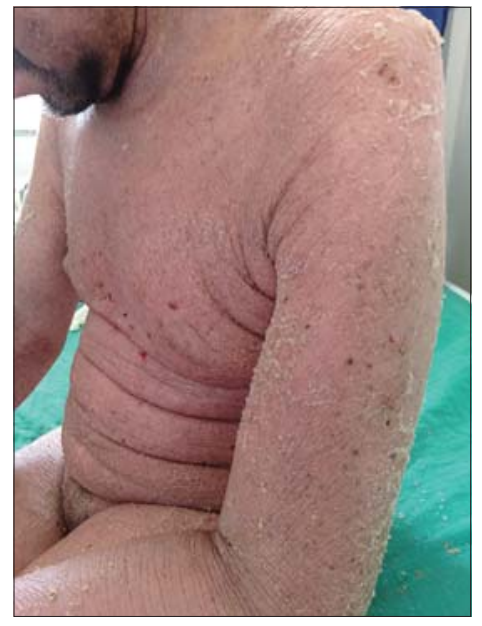

Figure 1: Dry and lichenified erythroderma.

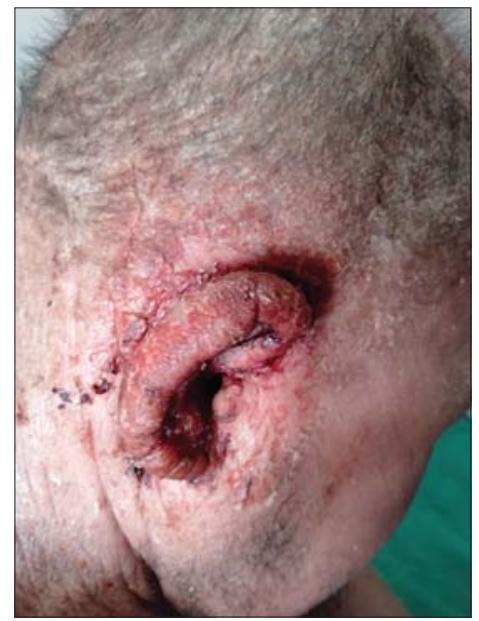

Figure 2: Infiltration of the ear's pinna with a carapace-like appearance of the scalp.

corticosteroid therapy to treat the syndrome, and rasburicase for hyperuremia. Despite this, the patient

\footnotetext{
How to cite this article: Abdelmouttalib A, Elghtaibi FZ, Sialiti S, Senouci K. Sézary syndrome preceded by mycosis fungoides and complicated by tumor lysis syndrome and macrophage activation syndrome. Our Dermatol Online. 2022;13(1):114-115.

Submission: 20.01.2021; Acceptance: 05.04.2021

DOI: 10.7241 /ourd.20221.32
} 


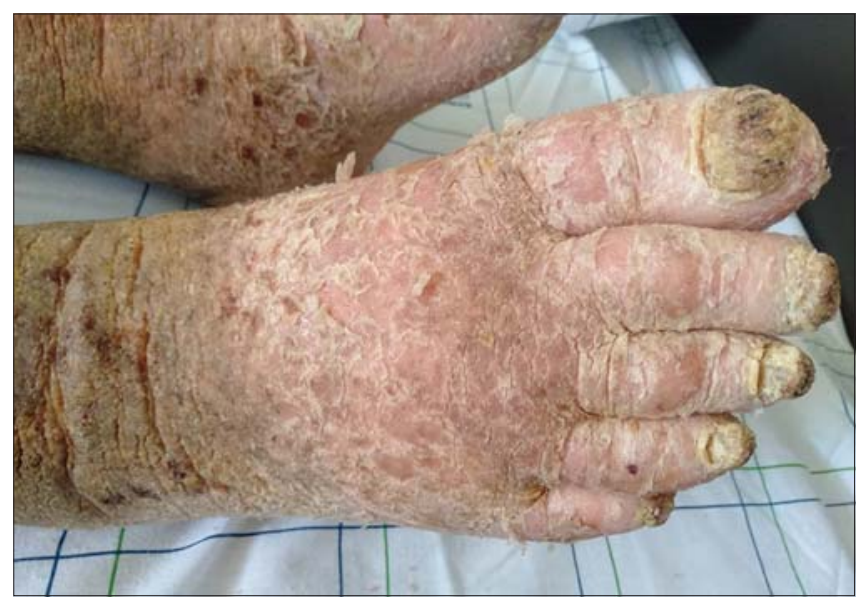

Figure 3: Xanthopachyonychia with wart and squamous plaques.

died before multiagent chemotherapy could have been started.

On rare occasions, SS may be preceded by a prior history of classic MF. The International Society for Cutaneous Lymphomas (ISCL) recommends that such cases be designated "SS preceded by MF" [2]. Traditionally, SS is defined as a leukemic form of CTCL associated with erythroderma. Sézary cells are a population of large lymphocytes in the peripheral blood, with grooved and lobulated nuclei, in the case of SS, numbering 1000 cells $/ \mu \mathrm{L}$ or more [2]. The histopathologic findings in the skin often resemble those observed in MF, with less prominent epidermotropism. As in MF, immunohistochemical studies showing a CD4 predominance and loss of pan-T-cell markers may be helpful. Lymph node involvement is characterized by the complete effacement of the nodal architecture by the infiltrating Sézary cells (2). The poor prognostic factors in Sézary syndrome include an advanced stage of the disease, an older age at onset, and large cell transformation [3]. While high response rates may be achieved with systemic chemotherapy, they are frequently short-lived and associated with significant toxicities [2].

The management of SS is complicated and requires multidisciplinary collaboration between dermatologists, hematologists, biologists, and reanimators.

\section{Consent}

The examination of the patient was conducted according to the principles of the Declaration of Helsinki.

The authors certify that they have obtained all appropriate patient consent forms, in which the patients gave their consent for images and other clinical information to be included in the journal. The patients understand that their names and initials will not be published and due effort will be made to conceal their identity, but that anonymity cannot be guaranteed.

\section{REFERENCES}

1. Larocca C, Kupper T. Mycosis Fungoides and Sézary Syndrome: An Update. Hematol Oncol Clin North Am. 2019;33:103-20.

2. Hristov AC, Tejasvi T, Wilcox RA. Mycosis fungoides and Sézary syndrome: 2019 update on diagnosis, risk-stratification, and management. Am J Hematol. 2019;94:1027-41.

3. Wu S, Jenkins F, Byrd R, Googe PB, Jolly PS. A case of bullous Sézary syndrome. Dermatol Online J. 2020;26:13030/qt6244g9rx.

Copyright by Asmae Abdelmouttalib, et al. This is an open-access article distributed under the terms of the Creative Commons Attribution License, which permits unrestricted use, distribution, and reproduction in any medium, provided the original author and source are credited.

Source of Support: Nil, Conflict of Interest: None declared. 